\title{
Delayed Onset Post-ERCP Pancreatitis (DOPE-P)
}

\author{
Vishal Khurana, MBBS, MD, DM, MNAMS* \\ Department of Gastroenterology, Metro Heart Institute with Multispeciality, Faridabad, Haryana, India
}

\section{"Corresponding author}

Vishal Khurana, MBBS, MD, DM, MNAMS

Consultant, Department of Gastroenterology, Metro Heart Institute with Multispeciality, Faridabad, Haryana, India; E-mail: vishdoc24@gmail.com

\section{Article information}

Received: May $7^{\text {th }}$ 2018; Accepted: August 2 $2^{\text {nd }}, 2018$; Published: August $8^{\text {th }}, 2018$

\section{Cite this article}

Khurana V. Delayed onset post-ERCP pancreatitis (DOPE-P). Pancreas Open J. 2018; 2(I): e8-e9. doi: 10.17/40/POJ-2-e008

$\mathrm{P}$ ost Endoscopic retrograde cholangiopancreatography (ERCP) Pancreatitis (PEP) is defined as new onset or worsening of pain abdomen after ERCP with an elevation of pancreatic enzymes (amylase/lipase) more than 3 times upper limit of normal after 24 hours of procedure and prolongation of hospital stay/ planned admission. ${ }^{1,2,3}$ The overall incidence of PEP is estimated to be $3-10 \% .^{1,2,3}$ Various risk factors found in multivariate trials are divided into patient-related risk factor (prior PEP, female sex, young patient, normal bilirubin, previous recurrent pancreatitis, suspected sphincter of Oddi dysfunction, absence of chronic pancreatitis) and procedure-related risk factors (difficult cannulation i.e. $>10$ minutes cannulation time, repetitive pancreatic duct guide wire cannulation, pancreatic duct contrast injection, pancreatic sphincterotomy, endoscopic papillary large-balloon dilatation of an intact sphincter). Placement of prophylactic pancreatic stents (PPSs) usually advocated in high-risk patients and reduced PEP rate by $60-80 \% .^{4,5} 3 \mathrm{Fr}$ stents have higher migration rate and hence 5 Fr stents are superior to $3 \mathrm{Fr}$. Studies have shown that if placement of pancreatic stent is attempted but fails risk of PEP increases. $^{6}$

There is scarce data available on incidence and severity of delayed onset post ERCP pancreatitis (DOPE-P). ${ }^{7,8}$ DOPE-P is defined as the development of features of pancreatitis after the first 24 hrs of ERCP. It can occur in two situations: either early migration of prophylactic pancreatic duct (PD) stent within first day of ERCP or after endoscopic removal of PD stent. A retrospective cohort study of 230 patient undergoing PPS removal has shown $3 \%$ incidence of pancreatitis after pancreatic stent removal. Statistical significant risk factors found in this study were use of $5 \mathrm{fr}$ a stent, stent with internal flange and history of PEP after initial ERCP. ${ }^{8}$ Probable etiology of DOPE-P is trauma to PD caused by stent removal. There is a need for a prospective trial for incidence, severity and prevention of DOPE-P. Judicious use of PPS in the only high-risk ERCP with slow removal of PPS within
5-10 days or pharmacoprophylaxis with rectal Nonsteroidal antiinflammatory drug (NSAIDs), if stent removal done after 10 days, it may theoretically decrease the incidence of DOPE-P. Guidelines recommends evaluation of self-migration of PPS within 5-10 days of placement and endoscopic removal if stent do not migrate with 5-10 days.

\section{CONFLICTS OF INTEREST}

None.

\section{REFERENCES |}

1. Dumonceau JM, Andriulli A, Elmunzer BJ, et al. Prophylaxis of post-ERCP pancreatitis: European society of gastrointestinal endoscopy (esge) guideline - updated june 2014. Endoscopy. 2014; 46(9): 799-815. doi: 10.1055/s-0034-1377875

2. ASGE Standards of Practice Committee, Anderson MA, Fisher L, Jain R, et al. Complications of ERCP. Gastrointest Endosc. 2012; 75(3): 467-73. doi: 10.1016/j.gie.2011.07.010

3. ASGE Standards of Practice Committee, Chandrasekhara V, Khashab MA, Muthusamy VR, et al. Adverse events associated with ERCP. Gastrointest Endosc. 2017; 85(1): 32-47. doi: 10.1016/j. gie.2016.06.051

4. Mazaki T, Masuda H, Takayama T. Prophylactic pancreatic stent place- ment and post-ERCP pancreatitis: A systematic review and meta-analysis. Endoscopy. 2010; 42: 842-853. doi: 10.1055/s-00301255781

5. Choudhary A, Bechtold ML, Arif M, et al. Pancreatic stentsfor prophylaxis against post-ERCP pancreatitis: A meta-analysis and systematic review. Gastrointest Endosc. 2011; 73: 275-282. doi: 
10.1016/j.gie.2010.10.039

6. Choksi NS, Fogel EL, Cote GA, et al. The risk of post-ERCP pancreatitis and the protective effect of rectal indomethacin in cases of attempted but unsuccessful prophylactic pancreatic stent placement. Gastrointest Endosc. 2015; 81(1): 150-155. doi: 10.1016/j. gie.2014.07.033
7. Freeman ML. Use of Prophylactic Pancreatic Stents for the Prevention of Post-ERCP Pancreatitis. Gastroenterol Hepatol (N Y). 2015; 11(6): 420-422.

8. Moffatt DC, Coté GA, Fogel EL, et al. Acute pancreatitis after removal of retained prophylactic pancreatic stents. Gastrointest Endosc. 2011; 73(5): 980-986. doi: 10.1016/j.gie.2011.01.012 